\title{
EL CUERPO INVESTIGADOR, EL CUERPO INVESTIGADO Una aproximación fenomenológica a la experiencia del puerperio
}

\author{
ANa SABRINA Mora \\ Licenciada en Antropología y estudiante del Doctorado en Ciencias Naturales con \\ orientación en Antropología de la Universidad Nacional de la Plata, Argentina. \\ Docente-investigadora de la Universidad Nacional de La Plata, UNLP. Becaria \\ del Consejo Nacional de Investigaciones Científicas y Técnicas, CONiCET. \\ sabrimora@gmail.com
}

\begin{abstract}
Resumen
[l OBJETIVO DE ESTE ARTÍCULO ES EXPLORAR LA UTILIDAD DE LAS DESCRIPCIONES FENOMENOLÓGICAS, Lincluyendo las experiencias de quien realiza la investigación, como parte de los análisis socioantropológicos sobre el cuerpo y la sexualidad, en especial, para aproximarse al estudio del puerperio y a algunas experiencias que suelen asociarse a él en la contemporaneidad occidental. Intenta, además, integrar la propuesta metodológica de la fenomenología con los marcos analíticos postestructuralistas. Se parte de la idea de que la observación de acontecimientos vitales intensos como el parto y el puerperio, es una vía de acceso al conocimiento de todas aquellas experiencias que desde el cuerpo repercuten sobre la subjetividad, y considera al cuerpo y al sujeto como una unidad indisoluble, que sólo puede comprenderse desde su imbricación, tal como lo establece la perspectiva del embodiment.
\end{abstract}

Palabras Clave: puerperio, embodiment, fenomenología

\section{RESEARCHER BODY, RESEARCHED BODY.}

\section{A PHENOMENOLOGICAL APPROACH}

TO THE PUERPERIUM EXPERIENCE

\begin{abstract}
THE OBJECTIVE OF THIS ARTICLE IS TO EXPLORE THE USEFULNESS OF PHENOMENOLOGICAL DESCRIPTIONS, including the detailed experiences of who conducts the research, as part of a socioanthropological research on the body and sexuality in particular, for the analysis of puerperium and some associated experiences in the contemporary Western world. It attempts to integrate phenomenological methods and postructuralist analytical frameworks. It starts with the idea that the observation of intense vital events such as childbirth and puerperium is a way to acquire knowledge of all those bodily experiences that have repercussions on subjectivity, and considers the body and the subject as an indissoluble unit that can only be understood in this imbrication, as proposed by the notion of embodiment.
\end{abstract}

KEY WORDS: puerperium, embodiment, phenomenology

Revista Colombiana de Antropología

Volumen 45 (I), enero-junio 2009, pp. II-38 
El cuerpo investigador, el cuerpo investigado. Una aproximación fenomenológica a la experiencia del puerperio

E

N ESTE ARTíCULO PERSIGO UN DOBLE OBJETIVO. POR UN LADO, EXPLORAR la utilidad del conocimiento corporeizado y de las descripciones fenomenológicas, como parte de las investigaciones socioantropológicas sobre el cuerpo, y sobre el cuerpo y la sexualidad, en particular. Por otro lado, me aproximo al puerperio y a algunas experiencias que suelen asociarse a él, en la contemporaneidad occidental. El análisis de acontecimientos vitales intensos como el parto y el puerperio, es vía de acceso al conocimiento de todas aquellas prácticas que a partir del cuerpo repercuten en la subjetividad, pone en cuestión los términos del dualismo cartesiano y considera al cuerpo y al sujeto como una unidad, en la que sus términos son indisolubles y sólo pueden comprenderse desde su imbricación.

En este trabajo ensayo con preguntas y respuestas acerca de las posibilidades del cuerpo como productor de conocimiento y de subjetividad. Tomo como base empírica el caso de mi propia experiencia del puerperio y considero que ésta produce conocimiento; las descripciones fenomenológicas son cruciales para comprender los efectos de la corporeidad sobre la subjetividad. Mi puerperio (como el de tantas mujeres) estuvo compuesto por una serie de acontecimientos, vivencias, percepciones, sensaciones y prácticas que se conectaron, entrecruzaron, encadenaron e hilvanaron entre sí, en una trama mutable y que a su vez se pusieron en relación con perspectivas de análisis que proponen pensar el mundo y la vida con, a través y desde el cuerpo. Comenzaré por establecer la fundamentación teórico-metodológica del conocimiento corporeizado y de la inclusión de la descripción fenomenológica de las experiencias personales de la investigadora o del investigador en la producción de conocimiento académico. Luego, exploraré los caminos transitados por mí misma durante el puerperio y los senderos abiertos a partir de él. Intentaré contribuir a la integración de las perspectivas fenomenológicas y postestructuralistas, entendiendo que esta conjunción abre posibilidades fecundas al análisis de los fenómenos ligados al cuerpo, o más específicamente, al embodiment. 


\section{CONOCIMIENTO CORPOREIZADO: \\ LA ETNOGRAFÍA Y LAS EXPERIENCIAS CORPORALES}

${ }^{\mathrm{N}}$

N DIVERSAS OCASIONES SE HA DESTACADO LA NECESIDAD DE NO OLVIDAR el

lugar que el investigador ocupa en el contexto de investigación, como un sujeto social que produce una mirada sobre otros sujetos sociales. Entre los más sobresalientes podemos citar a Pierre Bourdieu quien advierte que "cuando se aborda una práctica cultural cualquiera, [hay que] interrogarse a sí mismo como practicante de esa práctica” (2003: 25I-252) y sugiere el proceso de “autosocioanálisis" con el fin de "objetivar al sujeto objetivante", procurando "mirar y analizar los condicionamientos sociales que afectan al proceso de investigación, tomando como punto especial de la mirada al propio investigador y sus relaciones" (Gutiérrez, 2005: 229). Así, se pone al investigador en relación con sus pares, con las instituciones de su campo, con la realidad que analiza y con los sujetos cuyas prácticas investiga. En el mismo sentido, Martyn Hammersley y Paul Atkinson afirman que examinar el carácter reflexivo de la investigación social implica reconocer que somos parte del mundo social que estudiamos "y esto no es meramente una cuestión metodológica, es un hecho existencial" (I994: 29).

En otros casos, la consideración de sí mismo como sujeto socialmente situado que estudia a otros sujetos también socialmente situados, es entendida no sólo como una cuestión para tener en cuenta en relación con el control epistemológico del proceso de investigación, sino que es asimismo una herramienta de producción de conocimiento. Por ejemplo, en Tabu do corpo (2006 [I979]), José Carlos Rodrigues, pionero de la antropología del cuerpo en Brasil, afirma que, para el antropólogo, la introspección es un método válido de producción de conocimiento objetivo, partiendo de que no hay nada en la vida social que no pueda ser convertido en objeto de investigación, lo que incluye la propia conciencia. Con la premisa de que las experiencias son construidas socialmente y por eso son compartidas por sujetos que tienen un sistema de significaciones y representaciones sociales comunes, es decir, una cultura, se postula aquí que la transformación de sí mismo(a) en objeto de investigación, sin dejar de considerar las dificultades del distanciamiento necesario para transformar las propias experiencias en datos 
El cuerpo investigador, el cuerpo investigado. Una aproximación fenomenológica a la experiencia del puerperio

antropológicos, es un acercamiento útil para complementar las investigaciones etnográficas. Esto es en especial cierto cuando trabajamos sobre prácticas íntimas y ancladas en experiencias del cuerpo, que suelen ser, en particular, difíciles de acceder y comprender a cabalidad mediante observaciones y entrevistas. No se trata de abandonar estas técnicas de recolección de datos, sino de acompañarlas, complementarlas y enriquecerlas con la interrogación y la exploración por parte de quien investiga acerca de sus propias experiencias, vivencias y sensaciones, en relación con prácticas de las que formamos parte, en mayor o menor medida.

En esta misma línea, Renato Rosaldo (1989) ha defendido y ha puesto en práctica el abordaje autoetnográfico en el que se utiliza la propia experiencia del etnógrafo en función de la comprensión de sus objetos de estudio. Para conocer el grupo social investigado $\mathrm{y}$, en especial, para entender sus experiencias, emociones y motivaciones, las impresiones del etnógrafo constituyen un aporte que no debe desdeñarse. Al contrario, pueden tomarse como un punto de partida o una fuente de inspiración. Por esto, propone partir de las vivencias y de la implicación personal y usar lo interior para entender el afuera, para establecer un diálogo con el otro, con la emoción como vehículo para vincularse con los sujetos a los que estudia como con los lectores a los que dirige su producción científica. Otro aspecto interesante de esta propuesta radica en el hecho de que puede resolver el problema de la subjetividad y la reflexividad capitalizándolas de forma positiva sin caer en el exceso de autorreferencialidad que se les critica a otros autores postmodernos. Puede identificarse un paso previo a este tipo de aproximaciones en los enfoques interpretativos que reconocieron la pluralidad de voces confluyentes en la escritura etnográfica y a la gran importancia otorgada a las narraciones, que incluyen los relatos en primera persona del investigador(a), reivindicados hasta el punto de entender que el conocimiento etnográfico no deja de ser una historia más, que participa en el mundo de las narraciones sobre la vida. Todo esto condujo a una valoración positiva de la subjetividad y las emociones del investigador, que dejan de ser un elemento contaminante para convertirse en un material que aporta y enriquece la investigación.

Si se entiende la etnografía como una forma de acercarse a un objeto de estudio para realizar una inmersión en un espacio social concreto, con el objetivo de acceder a la perspectiva de 
los sujetos investigados, con el recurso de una serie de técnicas de recolección y registro de información, y con un marco teórico que se construye para poner en cuestión e interpretar los datos, el estudio de lo corporal desde una perspectiva socioantropológica, con técnicas etnográficas, plantea cuestiones metodológicas específicas. Debemos tener en cuenta que las técnicas utilizadas en las metodologías cualitativas se ponen en práctica en contextos en los que el investigador(a) forma parte e influye con su presencia, preguntas y comentarios, e incluso con su presentación y lenguaje corporal, del mismo modo que los sujetos investigados lo hacen sobre el investigador(a). Debemos ubicarnos como sujetos sociales que producen una mirada sobre otros, considerar que no sólo nuestro yo cultural se implica en la investigación, sino que los objetos de estudio y las formas de abordarlos o interpretarlos se construyen en relación con nuestro ser-en-el-mundo, y el proceso de investigación, así como el de formación vinculado, vuelve sobre nuestra existencia y se enlaza con la vida cotidiana.

Cuando se investigan prácticas corporales, se hace más profundo el problema que surge de manera recurrente en el momento de "interpretar lo interpretado" por los actores (Geertz, I997): el planteamiento de la distancia que existe entre lo que observamos o lo que nos es relatado en las entrevistas y la experiencia práctica y personal del cuerpo de los sujetos que investigamos. Si bien, en general, la relación del investigador con su objeto es la de quien está excluido del juego real de las prácticas que analiza, las sensaciones y vivencias corporales que pueden ocurrir al poner el cuerpo en la práctica estudiada, son una fuente de información nada desdeñable y se pueden volver cruciales para comprender las experiencias de quienes sí forman parte por completo del campo que estudiamos. Con las técnicas de recolección de información con las que contamos como antropólogas y antropólogos, es más sencillo conocer las prácticas por medio de las observaciones y comprender las representaciones mediante los discursos, que las experiencias del cuerpo. Entonces podemos preguntarnos: ¿Las experiencias, representaciones y prácticas ancladas en el cuerpo que nos interesa analizar, pueden ser comprendidas a través de la mediación de los discursos que las interpretan durante las entrevistas y las conversaciones? ¿Es posible comprenderlas basándose sólo en lo que se dice de ellas? Una vez que concluyamos que además del trabajo de campo tradicional se necesita la inclusión 
El cuerpo investigador, el cuerpo investigado. Una aproximación fenomenológica a la experiencia del puerperio

del conocimiento corporeizado producido desde la experiencia personal, surgen nuevas preguntas: ¿Se puede acceder mediante el análisis de la propia experiencia a aquellas sensaciones, experiencias y representaciones que nos son relatadas? ¿Cómo distinguir y vincular aquello que nos pasa al "poner el cuerpo" de aquello que nos es contado? ¿Cómo equilibrar la vivencia personal con los objetivos de la investigación y la pretensión de objetividad? ¿Cómo pasar todo lo aprendido con el cuerpo al lenguaje académico antropológico?

Una de las propuestas metodológicas para abordar lo corporal es la "sociología carnal" (carnal sociology of the body). Dentro de esta perspectiva, Nick Crossley (I995) ha dicho que la sociología del cuerpo, por lo común, maneja un enfoque que se centra en "lo que se le hace al cuerpo" (what is done to the body) y predomina la observación desde el punto de vista de su constitución como objeto significativo debido a discursos y como sujeto de prácticas de regulación o transformación. Frente a esto, propone sumar un enfoque que se ocupe de la comprensión de "qué es lo que el cuerpo hace" (what the body does), para otorgar a este un rol activo en la vida social, y tener en cuenta las bases incorporadas (embodied), es decir, internalizadas en y producidas por el cuerpo, los constituyentes prácticos y simbólicos de una formación social, a partir de considerar que el cuerpo no es sólo algo sobre lo que se actúa sino que también es productor de acción. Insinúa también que las ciencias sociales no se detengan en el estudio del cuerpo (of the body) sino que avancen hacia la inclusión de estudios desde el cuerpo (from the body). Que el cuerpo no sólo sea sujeto de investigación sino herramienta y sujeto de conocimiento, lo que implica dar centralidad al cuerpo actuante del investigador o la investigadora. El fundamento de esta propuesta podemos encontrarla en la necesidad de reconocer y restituir la dimensión carnal de la existencia, con frecuencia olvidada en las ciencias sociales, y de alejarse de las concepciones dualistas de la existencia. De acuerdo con Löic Wacquant, la sociología carnal "toma en serio, tanto en el plano teórico como en el metodológico y retórico, el hecho de que el agente social es, ante todo, un ser de carne, nervio y sentidos (en el doble sentido de sensual y significado), un 'ser que sufre' [...] y que participa del universo que lo crea y que, por su parte, contribuye a construir con todas las fibras de su cuerpo y su corazón” (2006: I5). Debemos reconocer tanto la implicación corporal que todo 
Volumen 45 (I), enero-junio 2009

conocimiento del mundo y de sí mismo tiene, como la necesidad de incluir aquel producido por nuestras propias experiencias corporales en el proceso de investigación. En las indagaciones sobre prácticas, representaciones y experiencias centradas en el cuerpo, se hace necesario un paralaje de investigación en el que el sujeto que investiga ponga su cuerpo en la práctica que estudia en algún momento.

La antropología del cuerpo ha establecido que esta es una construcción social y cultural y que la vida sociocultural construye prácticas y representaciones diversas del cuerpo. Aún así, esta construcción diversa (y desigual) de los cuerpos se hace sobre un sustrato común: El cuerpo, en tanto materialidad, en tanto encarnación del sujeto, es el sustrato compartido de la experiencia humana (Citro, 2006). La corporalidad del sujeto, entonces, abarca tanto la dimensión sociocultural (los modos de representación del cuerpo propio y el de los otros, las prácticas que sobre él y con él se realizan, las nociones de cuerpo y de persona), como la experiencia del cuerpo, que por supuesto está permeada por la dimensión anterior pero que puede no coincidir totalmente con ella. Por ejemplo, en el caso de la modernidad occidental, el modo hegemónico de entender al cuerpo está signado por el dualismo cartesiano, aunque no todas nuestras experiencias corporales se agotan en esta concepción ideológica. En palabras de Bryan Turner, el cuerpo "es la característica más próxima e inmediata de mi yo social, un rasgo necesario de mi situación social y de mi identidad personal" (1989: 33), y por esto, "percibir el mundo es reflejar las posibles acciones de mi cuerpo sobre aquél. De forma similar, experimento mi cuerpo como mío por medio de mi íntimo y concreto control sobre él" (Íbid: 82). En el análisis de las experiencias y sus conexiones se ve que desde el cuerpo se produce subjetividad, se producen formas especiales de vincularse con el mundo y con los otros y se produce conocimiento.

Friedrich Nietzsche y Maurice Merleau-Ponty han resaltado la experiencia del cuerpo al redefinir el cogito cartesiano, criticando la noción de sujeto como res cogita, es decir, caracterizado como aquello que piensa, y la visión del cuerpo como res extensa o como mera extensión material, de modo que ambos "construyen representaciones de la corporalidad que rompen con el paradigma cartesiano hegemónico en la modernidad y, al producir esta ruptura, postulan elementos que [...] definirían la experiencia 
El cuerpo investigador, el cuerpo investigado. Una aproximación fenomenológica a la experiencia del puerperio

común de la corporalidad" (Citro, 2006: 47-48). En Nietzsche, la esencia de la experiencia de la corporalidad es el movimiento, en el que el cuerpo se manifiesta con poder de transformar al mundo y a sí mismo. En el cuerpo residiría una voluntad de poder, uno que se ejerce desde el cuerpo y nos mueve a actuar sobre el mundo, cuya fuerza fundamental es la creación. De este modo, invierte los términos del racionalismo. Concibe al espíritu como instrumento del cuerpo y al cuerpo como "la razón en grande, la voluntad que obra como 'yo'” (I995 [1882]: 54). Merleau-Ponty, por su parte, sostiene que la experiencia de la percepción es un modo de ser fundador del ser, de la existencia. Quien percibe es un sujeto hecho carne con el mundo, un ser-en-el-mundo. La experiencia de la percepción es corporal, prerreflexiva, preobjetiva, basada en la indivisibilidad del vínculo del sujeto con el mundo. El concepto de carne hace referencia a "un sintiente sensible que no puede desligarse de su relación con un mundo" (Citro, 2006: 64) y que toma forma de cuerpo sólo cuando es pensado, objetivado, escindido de su condición existencial de carne. El sujeto de la sensación, según Merleau-Ponty, "no es ni un pensador que nota una cualidad, ni un medio inerte por ella afectado o modificado" (Citro, 2006: 63), sino "una potencia que co-nace (co-noce) a un cierto medio de existencia o se sincroniza con él [...] es una cierta manera de ser del mundo que se nos propone desde un punto del espacio, que nuestro cuerpo recoge y asume si es capaz de hacerlo" (Merleau-Ponty, I993 [1945]: 228). Al igual que en Nietzsche, los términos del cogito cartesiano son invertidos. El cuerpo es el que conoce en primer lugar, "este cuerpo que sabe del mundo más que nosotros” (Íbid: 253). Al proponer una síntesis entre ambos autores, la antropóloga argentina Silvia Citro concibe la experiencia del cuerpo incluyendo ambos modos de existencia: "Esa napa primaria de la experiencia perceptiva y práctica que la fenomenología ha sabido describir y ese modo activo y transformador que Nietzsche buscaba develar. La corporalidad del ser se hace carne con el mundo, pero también, otras veces, se confronta con ese mundo que se le resiste, se moviliza e intenta transformarlo" (2006: 94). Estas experiencias primarias de la corporalidad son las que están en juego en el puerperio, incluyen tanto la posibilidad de conocer y conocernos desde el cuerpo, como en la posibilidad de transformar nuestro mundo y a nosotras mismas. 
Volumen 45 (I), enero-junio 2009

En las dos últimas décadas, el concepto de embodiment ${ }^{\mathrm{I}}$ ha tenido una creciente importancia en la antropología del cuerpo. Ha sido caracterizado por Thomas Csordas (I993) como la condición existencial en la que se asientan la cultura y el sujeto. A esta perspectiva le sigue un enfoque metodológico, la fenomenología del cuerpo, que se basa en el reconocimiento del embodiment como sustrato existencial de la cultura y el sujeto ("necesario para ser"), y del cuerpo (en el sentido de cuerpo viviente, es decir, en su dimensión biológica y material) como punto de parti-

I. El concepto de embodiment se ha empleado como incorporación, corporificación, encarnación. da metodológico, más que como objeto de estudio. Las observaciones sobre el embodiment, de este modo, no son sólo estudios sobre el cuerpo, sino sobre la cultura y la experiencia, entendidas a partir del ser-en-el-mundo corporeizado (embodied), que buscan sintetizar la inmediatez de la experiencia corporeizada con la multiplicidad de sentidos culturales en que estamos inmersos (Csordas, 1999).

Michael Lambeck (1998) ha afirmado que tanto las experiencias monistas como las dualistas son inherentes a la condición humana. Propone la existencia de un dualismo universal presente en el pensamiento en todas las culturas, entendiendo al dualismo cartesiano como su versión occidental. El dualismo no siempre toma la forma de cuerpo-mente, es decir, cuerpo y mente no son categorías universales, pero sí existe siempre más de una categoría (por ejemplo, la tríada cuerpo-mente-espíritu, o la división entre cuerpo activo y vegetativo, entre otras posibilidades) para hablar de los dominios que cubren esos dos referentes. Reconocer el dualismo mente-cuerpo no quita que este no pueda ser trascendido en la práctica y tampoco implica asumir una distinción tajante entre fenómenos estables que se relacionan de modo definitivo. Al considerar el caso de la oposición que hacemos entre mente y cuerpo, Lambeck entiende que estas no son categorías contrarias ni opuestas, sino inconmensurables; es decir, no pueden ser medidas desde un criterio común, no existe entre ellas una posición intermedia, no se excluyen la una a la otra, cada una no es la ausencia de la otra, no son suficientes, cada una por su lado, para describir la experiencia humana; mente y cuerpo están implicados uno en el otro, no hay uno sin el otro. Esta inconmensurabilidad entre mente y cuerpo sugiere que podrán ser producidas tanto en ideas monistas como dualistas en 
El cuerpo investigador, el cuerpo investigado. Una aproximación fenomenológica a la experiencia del puerperio

relación con la experiencia humana, pero como esta tiene algo genuinamente dual, entonces los términos para expresarla son inconmensurables. La mente-cuerpo puede enfocarse a partir del modo en que es representada en la mente o del modo en que es incorporada, vivida en el cuerpo: aun cuando mentalmente podamos distinguir la mente del cuerpo, estos convergen en la práctica. Así, "si, desde la perspectiva de la mente, el cuerpo y la mente son inconmensurables, entonces desde la perspectiva del cuerpo, están integralmente relacionadas" (Lambeck, I998: II2). Los cuerpos sirven como íconos, índices y símbolos de la sociedad y de los individuos, pero no son sólo eso. En todas las prácticas situadas, las personas y por ende las relaciones sociales no están sólo significadas sino constituidas de manera activa por los cuerpos. La subjetividad y la sociabilidad imparten significado al cuerpo y hacen que este sea posible; pero también es cierto que el cuerpo no es sólo su representación, y que tiene un carácter productor de la subjetividad y de la sociabilidad. La cuestión, en suma, no es dar vuelta a los valores de la ecuación cartesiana o de trascender el dualismo celebrando el cuerpo a expensas de la mente o reducir las categorías mente-cuerpo a una sola entidad, sino de ver siempre cada uno a la luz del otro y tener en cuenta las dimensiones productivas de esta relación de inconmensurabilidad. Al entender el embodiment como la conjunción de la mente y el cuerpo, podemos reconocer que las prácticas corporeizadas (embodied) se llevan a cabo por agentes que pueden producir una objetivación conceptual sobre esas prácticas. El embodiment siempre deja abierta la posibilidad para la autorreflexión y para comprender las implicaciones de las posibilidades de agencia (capacidad de acción).

\section{LA EXPERIENCIA DEL PUERPERIO}

N LA ACTUALIDAD, EN NUESTRA SOCIEDAD, LA MAYOR PARTE DE LOS
partos tienen lugar en ambientes médicos mediados por di-
versas tecnologías. Madeleine Akrich y Bernike Pasveer han
estudiado los modos en que las prácticas médicas intervienen
en la articulación entre el cuerpo y el yo en las mujeres durante
el trabajo de parto y el nacimiento. En estas experiencias, el 
cuerpo, corrientemente mudo y controlado, "toma la iniciativa" (2004: 67) y "experimenta por sí mismo" (Íbid, 68), y se produce un conflicto entre el "cuerpo-en-trabajo-de-parto" y el yo incorporado (embodied self). El primero, en ese momento escapa a los controles que por lo usual se pueden ejercer desde el segundo. En este conflicto intervienen las prácticas médicas, producen articulaciones que responden a su propia lógica, con la consiguiente alienación del propio parto y del cuerpo. Las publicaciones médicas suelen definir lo que llaman puerperio normal (no hablaremos aquí de lo que se considera "puerperio anormal" o "puerperio patológico" desde la práctica psiquiátrica y médica, concepciones que transitan la senda de la medicalización e incluso la anatomización de procesos más complejos) como un período en el que se producen transformaciones progresivas de orden anatómico y funcional, que hacen retroceder de manera paulatina todas las modificaciones (fisiológicas, anatómicas y endocrinas) producidas durante la gestación y que tienen como fin restituir las condiciones del estado pregrávido, con excepción de la glándula mamaria que experimenta un gran desarrollo. La visión médica acerca de este período, sus características, su desarrollo normal, sus implicaciones y su resolución, se centra en una serie acotada de sucesos anatómicos (y, supuestamente, también psicológicos, pero como se referirían en última instancia a los cambios hormonales, continuarían en el plano de lo orgánico) que siguen al parto y abarcan un breve intervalo. De forma convencional se extiende desde la finalización del parto hasta 45-60 días postparto. Por lo general, se divide en tres o cuatro etapas: la primera es el puerperio inmediato, que comprende las primeras 24 horas e incluye los mecanismos hemostáticos uterinos; la segunda, el puerperio mediato o propiamente dicho, abarca del segundo al décimo día e incluye los mecanismos involutivos y el inicio de la lactancia; la tercera, el puerperio tardío, se extiende aproximadamente hasta los 45 días luego del parto y finaliza con el retorno de la menstruación. En ocasiones se denomina a la tercera etapa puerperio alejado, y se agrega una cuarta llamada puerperio tardío, que abarcaría el período de lactancia exclusiva hasta los seis meses de vida del bebé. Desde esta visión, entonces, el puerperio se trataría de una "vuelta a la normalidad" para el cuerpo de la mujer que acaba de parir, en la que se deja atrás el cuerpo embarazado. Una muestra de esta concepción podemos encontrarla incluso en la definición 
El cuerpo investigador, el cuerpo investigado. Una aproximación fenomenológica a la experiencia del puerperio

de la palabra "puerperio" en la edición 2004 del diccionario de la Real Academia Española: "Del lat. puerperium. I. m. Período que transcurre desde el parto hasta que la mujer vuelve al estado ordinario anterior a la gestación. 2. m. Estado delicado de salud de la mujer en este tiempo" (disponible en www.rae.es).

Esta concepción del puerperio debe entenderse en el marco del creciente proceso de medicalización producido desde principios del siglo XX, por medio del cual la maternidad ha sido cooptada y muy influenciada por los discursos del higienismo y de la eugenesia. Así, obstetras y pediatras se han constituido en interlocutores privilegiados y en intermediarios de la relación madre-bebé, en general, desde perspectivas que reproducen las significaciones del sistema sexo-género vigente (naturalización de la función de las mujeres como reproductoras de la especie y de la sociedad, asociación directa mujer-madre y énfasis en la heteronormatividad), y que transforman al embarazo, el parto y las diversas prácticas del cuidado de los niños en prácticas científicas (por ejemplo: cuánto aumentar de peso en el embarazo, cómo, con quiénes y dónde parir, cómo amamantar, alimentar, higienizar o hacer dormir a las y los bebés de una manera que se considera adecuada y racional).

A su vez, este proceso de medicalización de la maternidad forma parte de un proceso aún más complejo. La red de somatopoder y de bio-poder que controla y regula los cuerpos individuales y las poblaciones. En palabras de Michel Foucault: "Las relaciones de poder pueden penetrar materialmente en el espesor mismo de los cuerpos sin tener incluso que ser sustituidos por la representación de los sujetos. Si el poder hace blanco en el cuerpo no es porque haya sido con anterioridad interiorizado en la conciencia de las gentes" (1992 [1977b]: 156). Estas redes de relaciones de poder que atraviesan y penetran en los cuerpos tienen una doble forma de ejercicio: La disciplina (o anátomopolítica del cuerpo humano) y la bio-política. La primera de las tecnologías de poder, que se desarrolló desde el siglo XVII, se centró en el cuerpo concebido como máquina e involucraba y trataba de asegurar "su educación, el aumento de sus aptitudes, el arrancamiento de sus fuerzas, el crecimiento paralelo de su utilidad y su docilidad, su integración en sistemas de control eficaces y económicos" (Foucault, 2002 [1976]: 168), tendiendo a una maximización de la capacidad productiva y a la minimización de la capacidad de resistencia de los seres humanos, mediante 
el control de sus cuerpos. La segunda, formada hacia mediados del siglo XVIII, se centró en el cuerpo-especie, "en el cuerpo transido por la mecánica de lo viviente y que sirve de soporte a los procesos biológicos: la proliferación, los nacimientos y la mortalidad, el nivel de salud, la duración de la vida y la longevidad, con todas las condiciones que pueden hacerlos variar" (Íbid), tomando a su cargo estos problemas por medio de una serie de intervenciones y controles reguladores de la población. En la actualidad, de acuerdo con Gilles Deleuze, las sociedades de control sustituyen las disciplinarias. Los mecanismos de control se caracterizan por ser ondulaciones o modulaciones que cambian constantemente y en las que "los individuos han devenido 'dividuales' y las masas se han convertido en indicadores, datos, mercados o 'bancos'” (I999b: 28I); mientras que la disciplina tenía una "larga duración, infinita y discontinua" (Íbid, 284), el control "se ejerce a corto plazo y mediante una rotación rápida, aunque también de forma continua e ilimitada" (Íbid).

De todos modos, la manera médica hegemónica de entender el puerperio no es la única posible. Desde otras miradas, se entiende como el período transitado entre el nacimiento y casi los dos primeros años de vida del o la bebé; es decir, va mucho más allá del puerperio decretado por la medicina, tanto de forma temporal como cualitativa. Más aún, estos primeros años corresponderían a la etapa más intensa del puerperio, que en realidad puede extenderse por un período más largo. Lejos de reducirse a un momento de cambios anatómicos, fisiológicos y endocrinos, es un período en el que aparecen fenómenos particulares y de gran potencia movilizadora, asociados a la experiencia de dejar de ser dos en el cuerpo de una para pasar a ser dos separados(as) pero fusionados(as). De acuerdo con Laura Gutman (2004, 2005), estos fenómenos son: la fusión emocional mamá-bebé, el encuentro con "la propia sombra", la aparición de "la madre interior que nos habita" y "la unión vida-muerte" o "puerperio-duelo". Esta autora describe el parto como un inmenso quiebre durante el que se abre tanto el cuerpo como lo que ella llama el "alma" de la madre y provoca que emerja desde las profundidades de su ser "lo desconocido, lo inconciente, la memoria, el pasado y los sentimientos relegados" (2004: 29); esto incluye al bebé que nosotras mismas fuimos, la madre que tuvimos y que incorporamos, otros acontecimientos de la biografía personal y familiar y situaciones dolorosas que hemos preferido relegar a la "sombra" (término 
El cuerpo investigador, el cuerpo investigado. Una aproximación fenomenológica a la experiencia del puerperio

que toma de Jacques Lacan). La figura de la díada mamá-bebé intenta dar cuenta de la fusión emocional entre ambos, donde cada uno puede sentir y expresar (de distintas maneras) lo que le pasa al otro. Para la autora, la clave para transitar de la mejor manera posible el puerperio es permitir y desarrollar la fusión madre-bebé; esto posibilitaría tanto la resolución satisfactoria de este proceso como la salida progresiva de la fusión y la exploración superadora de las cuestiones conflictivas que hubieran emergido. Pero la fusión no se da siempre porque una serie de factores se suelen sumar para desalentarla: la separación que se hace de la madre y del bebé tras el parto, el ingreso en la vida de ambos de prácticas y concepciones médicas como los horarios fijos para amamantar, la incorporación de modelos de crianza y de creencias del tipo de las que desalientan el hecho de tener al bebé en brazos, las enormes dificultades que implican las relaciones y las tareas cotidianas y las presiones para reintegrarse con rapidez a la vida laboral, entre otros.

Cuando comencé a pensar en escribir este trabajo, mi hija tenía un poco más de un año, continuaba amamantándola y me encontraba sumergida, desde su nacimiento, en un volcán de sensaciones a las que no siempre podía dar sentido y que no siempre podía manejar. Me encontraba también en los inicios de mis estudios de doctorado, y hasta el momento la vida como nueva madre y como estudiante de postgrado se articulaban con trabajo, a modo de los sucesivos cuadros blancos y negros de un tablero de ajedrez. Esta sensación de desconexión se mantenía incluso en los momentos en que estudiaba o escribía con mi hija en brazos. Fue entonces cuando leí algunos textos de Maurice Merleau-Ponty y de Gilles Deleuze y los senderos bifurcados comenzaron a encontrarse cuando sentí que algunas de las cosas que ellos decían me servían para entender lo que vivía. Así, decidí escribir lo que me pasaba, mis sensaciones y vivencias, y agregué algunos apuntes de un diario personal que había llevado intermitentemente durante el embarazo y los tiempos que siguieron al parto. Del análisis de esos escritos surge este trabajo. A pesar de lo complejo que es separar unas de otras, me enfocaré en las experiencias centradas en los estados del cuerpo y no tanto en aquellas ligadas a estados emocionales y mentales; muchas de estas últimas provienen de experiencias corporales y en esos casos sí serán consideradas pero, por el momento, dejo de lado muchas de ellas que en general toman sentido en relación con la 
biografía personal y con lo vincular. Hablo de sensaciones y no de sentimientos, porque no me remito sólo a modos colectivos de ser, ver, decir o pensar sobre la realidad; no hablo de algo que puede ser nombrado por todos los sujetos que comparten una comunidad de sentido, sino de algo que afecta, trastoca, desequilibra, desacomoda el orden subjetivo, aquello que pasa a un nivel microperceptivo y que no siempre es posible nombrar. La experiencia interna del puerperio se basa en sensaciones de este tipo. Por experiencia no me refiero a algo lineal, continuo, sino a una experiencia de discontinuidad, de inestabilidad, en parte caótica, sobre la que no siempre tengo control, que irrumpe y desarticula una manera de ser, de ver, de pensar, de decir, de actuar; una experiencia del orden del suceso.

En relación con la maternidad, se pueden distinguir tres tipos de acontecimientos que marcan profundos cambios en el cuerpo y en la subjetividad:

I. El embarazo. Dentro de las transformaciones vinculadas al embarazo, la experiencia corporeizada (embodied) central es la de tener-ser un cuerpo que es mío y que a la vez no lo es, un cuerpo que es sede de otro y que se adecua a la presencia de este otro; es decir, la sensación de "soy mi cuerpo, que es mío, pero a la vez no es mío”. Esto incluye la experiencia de un cuerpo que pasa por cambios sobre los que no se tiene control y que responde a las necesidades de otro que crece. Estas alteraciones hacen que durante el embarazo el cuerpo propio (aun en su carácter de habitado por otro) adquiera una presencia ineludible e inocultable, de una marcada centralidad en la vida cotidiana, tanto desde vivencias agradables (como el sentir los movimientos del otro que nos habita) como desagradables (como los dolores o los malestares físicos), que en realidad no llegan a ser incómodos por completo al saber que son parte de un proceso deseado. Junto con esto, la centralidad del cuerpo se enlaza con la sensación de estar conectada con algo que en mi caso sentí como un lado animal del ser, esto es, objeto de procesos que ocurren por el sólo hecho de formar parte de una especie. El modo en que se viven estas cuestiones, que puede sintetizarse en la experiencia de un cuerpo propio pero que no es sólo mío y en la centralidad del cuerpo desde la inclusión de un otro, desde sus transformaciones y desde procesos biológicos (por supuesto, inteligibles y cargados de sentido desde lo cultural), depende del modo en 
El cuerpo investigador, el cuerpo investigado. Una aproximación fenomenológica a la experiencia del puerperio

que esté situada socialmente la mujer que las vive, del lugar que el embarazo ocupa dentro de su biografía, sus proyectos y sus deseos y de la manera en que el embarazo se desarrolla, entre otras variables. El modo en que es experimentado repercutirá en cómo sean vividos el parto y el puerperio.

2. El parto. Es una experiencia que puedo describir como de desgarro y de pasaje, tremendamente intensa. El grado cero del puerperio, que es el parto, es un acontecimiento que puede iniciar nuevas conexiones en la vida de una persona; es un instante en el que se puede sentir que estamos ante el sentido de la existencia, que las fuerzas del universo confluyen en una misma. Gilles Deleuze y Félix Guattari, al referirse a la manera en que se construyen los rizomas, han escrito que pueden iniciarse cuando "un rasgo intensivo se pone a actuar por su cuenta, una percepción alucinatoria, una sinestesia, una mutación perversa, un juego de imágenes se liberan y la hegemonía del significante es puesta en entredicho" (I994a: 20). Esta descripción resuena en algunos puntos en lo que se siente durante un parto sin anestésicos. En estado de conciencia alterada (al que contribuye el dolor), muy intenso, tras el cual no es posible ser la misma o verse de la misma manera. El dolor, junto a la sensación de que por el propio cuerpo ha pasado toda la potencia de la creación, que culminará en la vida de una hija o de un hijo, es un dolor que no es sufrimiento, sino puerta hacia algo nuevo y hacia una sensación de poder, de ser capaz de hacer cualquier cosa. Así, el parto inicia un rizoma (Op. cit.), una serie de conexiones con el pasado, con el futuro, con distintas dimensiones del presente, con segmentos de vidas de otros, con diversas vidas que conviven en una misma. El modo en que el parto es vivido y el juego entre la posibilidad de transitarlo, con libertad y los diversos grados de intervención de las tecnologías médicas, tendrán impacto en cómo sea experimentado el puerperio.

3. El puerperio. Tras meses de experimentar el cuerpo propio como "mío pero no mío", habitado por otro, y tras la experiencia intensa del parto, en el puerperio se vuelve al cuerpo propio, pero sin ser aún sólo mío porque sigue siendo del otro, sobre todo por medio del amamantamiento, fuente y medio para la vida de otro, y porque es de un sujeto que continúa sintiéndose una con ese otro (de lo que da cuenta el fenómeno de la fusión mamá-bebé). Además, ese cuerpo propio ya no es el mismo que 
era antes de ser sede de otro. Esto lleva a sentirse otra, con otro cuerpo que no es el que se tenía antes ni durante el embarazo, y que se experimenta de una nueva forma, que no se reconoce, que se siente vacío, que duele y que también da felicidad en la plenitud de sensaciones como la de amamantar o sentirse deshecha, rota, desmontada, desestructurada, descontrolada. Al pasar de ser dos en el cuerpo de una, a luego ser una que a la vez es dos, viviendo en dos cuerpos, conectados de múltiples maneras, es mucho lo que hay que recomponer de sí misma, del modo en que me entiendo, del modo en que llevo mi vida. A la vez, la sensación de la presencia de un "ser animal", presente desde el embarazo, se profundiza: desnuda, lastimada, suturada, chorreando e inundada de sangre y de leche, se es carne. En los días que siguen al parto, la experiencia de ser carne, y poco más que eso, es muy poderosa.

Durante el puerperio se presenta una posibilidad de opción: negarse, de forma conciente o inconciente, a lo que sucede y esforzarse trabajosa y angustiosamente por "volver a la normalidad". Es decir, sujetarse a lo que se espera desde el mundo del afuera de la díada y la fusión o dejarse llevar por ella con un espíritu de exploración y de autoconocimiento, para luego reconstituir y reconfigurar la propia subjetividad. Siempre que fue posible dejarse llevar por la fusión, la experiencia del cuerpo que es estar embarazada, parir, amamantar y cuidar a una bebé recién nacida, prima sobre toda reflexión conciente. Interpretar el llanto de una bebé y traducir "tiene hambre" o "tiene gases" o "quiere estar en brazos", conlleva una experiencia de reflexión, de racionalización, mediada por lo aprendido a lo largo de la vida (sobre todo en la experiencia como hija o como hermana, por ejemplo) y por los parámetros culturales acerca de la maternidad y de la crianza. Pero esta comprensión por traducción de las sensaciones del bebé no agotan en lo más mínimo la experiencia de la fusión. Esta no es traducible racionalmente de forma completa, es una sensación corporal y emocional, un estado del cuerpo que es a la vez un estado del ser. La fusión es una cuestión vital, una necesidad prerreflexiva, salida de la experiencia de la carne, de la sensación.

Estas experiencias, muchas de las cuales parten del cuerpo, tienen un impacto en la construcción de la subjetividad. Por un lado, la presencia de una persona que nos necesita para todo abre una disposición hacia otro, una disposición al cuidado de otro y la posibilidad de articular los propios deseos y prácticas en relación 
El cuerpo investigador, el cuerpo investigado. Una aproximación fenomenológica a la experiencia del puerperio

con, y en función de, deseos y necesidades suyos. Por otro lado, el hecho de haber experimentado lo que el propio cuerpo puede hacer (crear una nueva vida, parirla, amamantarla, sobrevivir al cansancio extremo), genera una sensación de poder que se ve reflejada en otros ámbitos de la vida y en el modo como el propio cuerpo es percibido, valorado y experimentado. El propio cuerpo se juzga desde un punto de vista diferente (centralmente, desde lo que el cuerpo es capaz de hacer, desde su potencia), que lleva a valorizarlo, a quererlo, a no verlo ya desde parámetros estéticos. Y también, estas experiencias pueden llevar a reconectarse con partes de una misma que se mantenían relegadas; así como durante el parto y el puerperio pueden revivirse situaciones traumáticas del pasado, también puede realizarse una exploración de sí misma que lleva a la búsqueda de aquello que nos da placer. En mi caso, en pleno puerperio, luego de muchos años de haberlo abandonado, sin motivo aparente, aunque creo que el motivo fue precisamente la reconexión con el propio cuerpo a la que he hecho referencia y a su revalorización desde nuevos criterios, volví a tomar clases de danza; luego de haberlo hecho durante siete años y de no haber bailado por I8, conocí a una maestra y hasta el día de hoy aprendo con ella, esta vez, danza contemporánea.

Soy conciente de que me refiero a la experiencia de embarazoparto-puerperio de quien ha tenido la posibilidad de elegir si quiere ser madre, en qué momento y de qué manera. Es una descripción que proviene de mi vida, que no pretende cubrir todos los casos posibles, pero muestra que la maternidad puede ser una experiencia de apertura, de conocimiento y de crecimiento. Desde los feminismos de la diferencia, se rescata la maternidad como una experiencia original de las mujeres, donde estas tienen la posibilidad de realizar una potencia, que, teniendo la posibilidad de optar con libertad no ser madre, puede ser una experiencia de libertad, en cuanto a "la libertad de trascender su propia subjetividad hacia el otro" (Agacinski, I999: 64), un otro que no es un medio sino un fin. Mientras los feminismos herederos de Simone de Beauvoir abogaban por el derecho a la igualdad de sexos con base en el derecho a la no diferencia, y por lo general ubicaban a la maternidad como una forma de sujeción de las mujeres que implicaba pasividad y que estas debían eludir si querían ser libres, otras feministas giraron hacia la reivindicación de las diferencias en el contexto de la igualdad y pusieron en discusión la 
asociación entre maternidad y ausencia de libertad y de creación. El problema radica en asociar maternidad con sometimiento a la naturaleza y con sujeción, con pasividad, cuando en realidad bajo ciertas condiciones está relacionada con la creación, con la realización de una potencia. Mujer no es sinónimo de madre, pero cuando lo es "no se mutila, cumple apasionadamente con una parte de ella misma" (Íbid: 68). No se trata de ningún modo de ver a la maternidad como el destino de las mujeres, ni como lo único que nos hace ser lo que somos, sino de verla como una elección posible que puede ser, dadas ciertas condiciones, una práctica de libertad. Es perfectamente comprensible que en determinado momento histórico y cultural haya sido necesario ponerla en cuestión e incluso negarla para poder romper con la asociación mujer-madre y con la larga cadena de inferiorización y de sometimiento que esta asociación ha implicado. Pero dadas ciertas circunstancias, con la herencia de estos cuestionamientos y sabiendo que podemos elegir libremente no ser madres, el hecho de elegir serlo es en sí una práctica de libertad que celebra la igualdad en la diferencia.

En el análisis de las experiencias y sus conexiones es posible ver que desde el cuerpo se produce subjetividad, se generan formas especiales de vincularse con el mundo y con los otros, se produce conocimiento. Las sensaciones y experiencias producidas en esta etapa de la vida, afectan, trastocan, desequilibran, desacomodan el orden subjetivo, desde un nivel microperceptivo. No hay duda de que el cuerpo es producido desde una historia colectiva, desde una biografía personal, familiar y vincular, desde un contexto histórico, desde un grupo social, desde situaciones, relaciones, miradas y controles. Pero el cuerpo no es sólo receptor, él también produce, desde él se produce. Con el cuerpo también se conoce y a la vez, lo que nos pasa en el cuerpo, incide en la construcción de nuestra subjetividad. Al partir de la perspectiva del embodiment, del hecho de ser un sujeto-cuerpo, podemos hacer el ejercicio analítico de separar estas dimensiones y afirmar que son experiencias que parten del cuerpo y repercuten en el sujeto.

El estado de fusión del puerperio puede ser un estado de resistencia ante el cuerpo digitalizado que Paula Sibilia desmenuza en El hombre postorgánico, ya que en varios aspectos se le opone. Es un cuerpo que vive en los ritmos lentos y blandos del bebé, en lugar de un cuerpo que se rige por circuitos digitales y que se adapta con facilidad a los ritmos de la producción capitalista 
El cuerpo investigador, el cuerpo investigado. Una aproximación fenomenológica a la experiencia del puerperio

global. Un cuerpo conectado con otro desde la emocionalidad y no desde la avidez y el control; una subjetividad que vive hilvanada delicadamente al cuerpo biológico, en vez de un cuerpo que se concibe inmaterial y formado por información. Nuestro mundo, "que incita a configurar ciertos tipos de cuerpos y subjetividades, y que al mismo tiempo se ocupa de sofocar otras modalidades posibles" (2006: 267-268), no es favorable al mantenimiento y a la protección del estado de puerperio. Pero este puede vivirse de todos modos y puede crear un nuevo territorio existencial. Puede ser una de las formas en que la vida se torna en objeto político, rebelándose "contra las fuerzas que intentan sujetarla, enriqueciendo las subjetividades y ampliando el campo de lo que existe" (Íbid, 269).

En su estudio sobre la artista plástica brasileña Lygia Clark, Suely Rolnik afirma que la producción de la vida se da en la afirmación de nuevas formas de existencia. Al hablar sobre la última obra de la artista plástica brasileña, Objetos relacionais (en la que ella interviene en el cuerpo del o la participante con distintos objetos de diversas texturas, tamaños, formas y contenidos, produciendo sensaciones, experiencias, percepciones, imágenes, que luego se relatan para darle sentido a lo vivido), la caracteriza como una "vivencia del desmontaje de nuestro perfil, de nuestra imagen corporal, para aventurarnos en la procesualidad hirviente de nuestro cuerpo-vibrátil sin imagen. [...] Estos extraños objetos creados por Lygia Clark tienen el poder de hacernos diferir de nosotros mismos" (1996: 343-344). Para conectarnos con esta vivencia, nos desconectamos de aquello que naturalizamos como familiar y conocido, nuestra realidad de la vida cotidiana, para dejarnos conducir hacia la frontera, hacia un estado en el que podamos vivir nuestro "cuerpo-bicho". Aquello que en nosotros escucha al "cuerpo-bicho" es un estado vital que puede llamarse "estado de arte", que se opone a lo que Deleuze ha denominado "estado de clínica", que es aquello que en nosotros lo silencia. El puerperio como estado vital implica superar el "estado de clínica" con el que se le asocia, es decir, la interiorización y la incorporación que a lo largo de nuestra historia individual y colectiva hemos hecho de la medicalización de la maternidad, para permitirnos entrar en un territorio desconocido que nos cuestiona y nos desestructura para volver a construirnos. En esta dimensión experiencial y experimental del puerperio es donde reside su potencia como práctica de resistencia a partir 
de "la movilización del estado de arte en la subjetividad" (Íbid, 345). El puerperio es un momento en que sentimos que bailamos al borde del abismo (parafraseando a Nietzsche), y en este borrar y difuminar de las fronteras entre mi cuerpo y el de otra u otro, en esta experiencia fluida de vivir en la frontera entre yo y mi bebé, entre quien yo era y quien puedo ser, entre la realidad y los ensueños que suelen poblarlo, entre el pasado, el presente y el futuro, reside su máxima potencia.

En cierta medida, el cuerpo y la subjetividad del puerperio, en fusión con la o el bebé, podría ser uno de los distintos modos de lo que Deleuze y Guattari han llamado "cuerpo sin órganos": Un cuerpo que está "lleno de alegría, de éxtasis, de danza" (I994b: 156), "una meseta, que comunica con las otras en un plan de consistencia" (Íbid, I63), que libera líneas de fuga, que es habitada por intensidades que hace pasar, produce y distribuye. El cuerpo sin órganos no es un organismo, es sólo un estrato del cuerpo sin órganos. "El cuerpo es el cuerpo. Está solo. Y no tiene necesidad de órganos" (Íbid, I63), por ello "el cuerpo está harto de sus órganos y quiere deshacerse de ellos, o bien los pierde" (Íbid, I56). El cuerpo del puerperio, constructor de subjetividad, no es un organismo con determinados órganos y funciones que han participado en una gestación y que luego de un parto vuelven a un "estado normal", es una zona de intensidad, cubierto, atravesado y rebosado por intensidades. Que el cuerpo no sea el organismo no significa que no pueda estar habitado también por órganos, una parte del cuerpo puede seguir siendo un órgano, pero determinando "una zona de intensidad como una huella o una zona sobre un CsO” (Íbid, I6I). Ciertos órganos en algún momento pueden ser sentidos e incluso pueden tomar el centro de la escena, por ejemplo, ante el dolor de las contracciones o el placer de amamantar, pero en estos casos estos órganos son también intensidades, son sentidos, vibran, con dolor o placer. De acuerdo con Ian Buchanan (1997), la cuestión central en Deleuze y Guattari es la pregunta: “¿Qué puede hacer el cuerpo?” Se debe entender el cuerpo sin órganos como el límite inalcanzable de lo que este es capaz de hacer, y lo que el cuerpo puede hacer aumenta cuando se incrementan las maneras en que puede ser afectado profundamente.

Según Michel Foucault, así como la normalización que se ejerce sobre los cuerpos tiene un impacto en los sujetos, las prácticas 
El cuerpo investigador, el cuerpo investigado. Una aproximación fenomenológica a la experiencia del puerperio

de libertad del cuerpo repercuten en la formación de subjetividades. Entre estas últimas, distingue las ideas de liberación de las prácticas de libertad. En las primeras subyace la creencia en "una naturaleza o un fondo humano que se ha visto enmascarado, alienado o aprisionado en y por mecanismos de represión" con lo que "bastaría con hacer saltar estos cerrojos represivos" (I996 [1982]: 95), cuando en realidad esa liberación no podría cumplirse sin la construcción de prácticas de libertad, que definirán nuevas formas de existencia. Las segundas van más allá de la emancipación de los mecanismos represivos e implican superar y controlar la apertura de un nuevo campo de relaciones de poder. De este modo, la resistencia está dada por un enfrentamiento con la forma como se ejerce el poder y conlleva la creación de nuevos modos de vida por fuera del modo establecido de ejercicio del poder. En la perspectiva foucaultiana la subjetivación tiene lugar cuando se producen prácticas de resistencia, de subversión, de creación de nuevos modos de existencia. Desde esta posición, la cuestión no es liberar al parto y al puerperio de la medicina para enmarcarlos en otras relaciones de poder y regímenes que le den una nueva definición y construyan parto y puerperio normales y un nuevo sujeto-puérpera, sujeto a esas prácticas de poder-saber y con determinadas reglas de cuidado de sí. Se trata de abrir territorios para que cada una pueda explorarse y explorar qué se abre en nosotras y a qué nos enfrentamos en esta nueva situación; se trata de transformar al parto y al puerperio en una práctica de libertad. Frente a la producción de sujetos normales y controlados, constituidos en la íntima relación entre los campos del saber y del poder, la construcción de subjetividades como modos de vida, en continuo proceso y cambio, puede ser una práctica de resistencia.

\section{LAS TRAMAS DE LA CIENCIA ALEGRE}

AS DIMENSIONES EXISTENCIALES QUE HE PUESTO A DIALOGAR, DESDE LAS más carnales hasta las más teóricas, fueron parte de la construc-ción de mi subjetividad e hicieron sentido en ella de manera conjunta. A primera vista podría parecer que la perspectiva del postestructuralismo, representada por Foucault, y la de la fenomenología representada por Merleau-Ponty, no pueden articularse. 
Volumen 45 (I), enero-junio 2009

Sin embargo, esto es posible si se consideran no como formas de abordar la realidad antagónicas sino complementarias (Crossley, I995, I996). Por ejemplo, Linda Martin Alcoff, en un llamado a reconsiderar el papel que desempeña la experiencia corporal en la producción del conocimiento, propone retomar a Merleau-Ponty y sumarlo a la perspectiva del feminismo postestructuralista que estima que "la experiencia y la subjetividad son producidas a través de la interacción de discursos" (1999: 122). Siguiendo a esta autora, "los intentos por explicar la experiencia como solamente constituida por macro-estructuras fallan al no tomar en cuenta, seria o adecuadamente, la experiencia vivida, personal e individual" (Íbid: 135). Sin negar la inscripción de las estructuras discursivas en los sujetos y sus cuerpos, se debe pensar que la experiencia no se produce sólo por la interacción entre los sujetos y los discursos, y que personalmente no experimento mi cuerpo como una construcción de estructuras, sino que muchas veces la experiencia corporeizada excede al lenguaje, aunque luego lo interprete desde él; así, se pueden entender la experiencia y el discurso como "imperfectamente alineados, con zonas de dislocación” (Íbid: 127), y a la experiencia como el lugar donde se desarrolla el discurso, no su resultado. En síntesis, sería productivo completar los informes discursivos de la construcción cultural de la experiencia, con descripciones fenomenológicas de la experiencia corporeizada y de los efectos de la corporeidad sobre la subjetividad en casos específicos y en ciertos tipos de prácticas.

$\mathrm{Al}$ entender que el proceso de conocimiento implica situarse en la frontera entre lo que sabemos (o creemos saber) y lo que ignoramos (o creemos ignorar), la propia vida es un lugar privilegiado para poner a prueba conceptos y prácticas. En Los intelectuales y el poder (1992 [1972]) Gilles Deleuze, en diálogo con Michel Foucault, propone utilizar los conceptos como cajas de herramientas, como instrumentos que sirvan, que operen, que funcionen. Deleuze ha afirmado que "un concepto sirve para vivir", no es algo que está separado de la experiencia. No sólo podemos poner a dialogar conceptos (producidos por las ciencias sociales y por la filosofía), sino también a estos con los preceptos (creados desde el arte, que consisten en maneras de ver y oír, en un conjunto de percepciones y sensaciones que se tornan independientes de quien las siente y que permanecen en 
El cuerpo investigador, el cuerpo investigado. Una aproximación fenomenológica a la experiencia del puerperio

quienes las recuperan) y los afectos (entendidos como maneras de sentir, como las sensaciones que impregnan nuestra vida) (Deleuze, 1999a). Esto debe servir para hacer visible lo que nos pasa de forma individual y colectiva, para interrogarnos acerca de nosotros mismos, sobre nuestra formación y nuestro contexto. La tensión entre nuestro cotidiano, los conceptos, la ciencia y el arte (ámbitos que son, cada uno por su parte, también espacios de tensión y de conflicto), pone a prueba tanto los saberes, su capacidad de operar y de hacer visible una realidad, como los supuestos y las certezas en los que basamos nuestra vida. Concebir los conceptos como cajas de herramientas invita a ponerlos en movimiento, a sacarlos de un campo, usarlos en otro y ver si funcionan, a ensayar cómo repercuten en mí, cómo me permiten pensar lo que me pasa, lo que les pasa a otros y otras, lo que pasa en el mundo.

En La gaya ciencia, Friedrich Nietzsche llama a producir una "ciencia alegre" surgida de la experiencia del cuerpo en el mundo, partiendo de que la vida es un medio para el conocimiento. En esta afirmación de la vida, del valor de lo sensible, nos cuenta: "No soy de los que tienen ideas entre los libros, en contacto con libros; estoy acostumbrado a pensar al aire libre, andando, saltando, escalando, bailando" (I995 [I882]: 249). En El ojo y el espíritu, Maurice Merleau-Ponty invita a que el pensamiento de la ciencia sea un "pensamiento alegre", situado en y desde el cuerpo, "este cuerpo actual que llamo mío" (I977 [I960]: II), partiendo del mundo sensible, para aprender a "posarse en las cosas mismas y en sí mismo" (Íbid, I2). En O Abecedário de Gilles Deleuze, este autor afirma que "alegría es todo lo que consiste en cumplir una potencia”, y propone seguir a Spinoza en la reivindicación de la alegría como un concepto de resistencia y de vida, como la manera de tener el máximo de nuestra potencia. En este sentido, Deleuze concibe a la alegría como realización, cumplimiento o conquista de una potencia de la que me creo capaz, que se puede manifestar en el sentimiento de estar alegre por haber llegado a ser lo que somos; por el contrario, la tristeza se produciría cuando me encuentro separado, como resultado de un poder ejercido sobre mí, de una potencia de la que yo me encontraba capaz, estando cierto o errado. Como vemos, explorar trayectos de la biografía personal, con apoyo en la filosofía, no tiene por qué implicar limitarse a la razón ni subsumir lo singular a lo abstracto, sobre todo si seleccionamos perspectivas filosóficas 
que rescatan maneras de pensar imbricadas con el mundo, con lo sensible, con la fuerza de lo viviente.

Por todo esto, el puerperio es un momento privilegiado para entender que existe una forma de conocimiento desde el cuerpo, un conocimiento corporeizado, constituido desde acontecimientos, sensaciones y experiencias que no se limitan a una reflexión conciente y que provienen de las experiencias de la carne. Recordemos la asociación de Merleau-Ponty entre co-nacer y conocer: Una parte de mí nació con mi hija y desde ahí nació otra forma de conocerme y de conocer.

\section{BibliografíA}

Agacinski, Sylviane. 1999. Política de los sexos. Taurus. Madrid.

Akrich, Madeleine y Bernike Pasveer. 2004. "Embodiment and disembodiment in childbirth narratives". Body \& Society Io: 63.

AlCOFf, Linda. 1999. "Merleau-Ponty y la teoría feminista de la experiencia”. Revista Mora $\mathrm{N}^{\circ}$ 5. Buenos Aires.

BOuRdiEu, PierRe. 2003. Creencia artística y bienes simbólicos. Elementos para una sociología de la cultura. Aurelia Rivera. Córdoba y Buenos Aires.

Buchanan, Ian. 1997. "The problem of the body in Deleuze y Guattari, or, What can a body do?". Body \& Society 3:73.

Citro, Silvia. 2004. "La construcción de una antropología del cuerpo: propuestas para un abordaje dialéctico". Ponencia en VII Congreso Argentino de Antropología Social. Córdoba. y los cuerpos de la Etnografía”, en Elina Matoso (comp.) El cuerpo in-cierto. Corporeidad, arte y sociedad. Letra Viva. Universidad de Buenos Aires. Buenos Aires.

Crossley, Nick. 1995. "Merleau-Ponty, the Elusive Body and Carnal Sociology". Body \& Society I: 43 .

1996. "Body-Subject/Body-Power: Agency, inscription and control in Foucault and Merleau-Ponty". Body \& Society 2: 99.

Csordas, Thomas. I993. "Somatic modes of attention". Cultural Anthopology (8) 2. 
El cuerpo investigador, el cuerpo investigado. Una aproximación fenomenológica a la experiencia del puerperio

Csordas, ThOMAs. 1999. "Embodiment and cultural phenomenology". Gail Weiss y Honi Feru Haber (eds.) Perspectives on embodiment. Routledge. Nueva York.

Deleuze, Gildes y Félix Guattari. 1994a. "Introducción: Rizoma”. En Mil mesetas. Capitalismo y esquizofrenia. Pre-Textos. Valencia.

. I994b. “¿Cómo hacerse un cuerpo sin órganos?”. En Mil mesetas. Capitalismo y esquizofrenia. Pre-textos. Valencia.

Deleuze, Gilles y Michel Foucault. 1992 [1972]. "Los intelectuales y el poder”. En Microfísica del poder. La Piqueta. Madrid.

Deleuze, Gilles. 1999a. O abecedário de Gilles Deleuze. Disponible en http://www.ufrgs.br/faced/tomaz/abcz.htm.

\section{Conversaciones. Pre-textos. Valencia.}

Foucault, Michel. I992 [ig77a]. "Poderes y estrategias”. En Microfísica del poder. La Piqueta. Madrid.

—. I992 [1977b]. "Las relaciones de poder penetran en los cuerpos”. En Microfísica del poder. La Piqueta. Madrid.

\section{Siglo XXI Editores. Buenos Aires.}

GeERTZ, CLIFFORD. I997. La interpretación de las culturas. Gedisa. Barcelona.

GutTÉRREZ, Alicia. 2005. "El sentido práctico: La lógica de la práctica y el proceso de reflexividad en Pierre Bourdieu". Revista Complutense de Educación 2 (I6). Universidad Complutense de Madrid. Madrid.

Gutman, Laura. 2004. Puerperios y otras exploraciones del alma femenina. Del Nuevo Extremo. Buenos Aires.

2005. La maternidad y el encuentro con la propia sombra. Del Nuevo Extremo. Buenos Aires.

Hammersley, Martyn y Paul Atkinson. 1994. Etnografía. Métodos de investigación. Paidós. Barcelona.

LAMBeCK, Michael. 1998. "Body and mind in mind, body and mind in body: Some anthropological interventions in a long conversation". En M. Lambeck, y A. Strathern (eds.) Bodies and persons. Comparative perspectives from Africa and Melanesia. Cambridge University Press. Cambridge.

Merleau-Ponty, Maurice. I977 [1960]. El Ojo y el Espíritu. Paidós. Buenos Aires.

Merleau-Ponty, Maurice. 1993 [1945]. Fenomenología de la percepción. Planeta. Buenos Aires. 
Nietzsche, Friedrich. 1995 [I882]. La Gaya Ciencia. Cofás, Madrid.

Rodrigues, José Carlos. 2006 [I979]. Tabu do corpo. Editora Fiocruz. Río de Janeiro.

RolNik, Suely. I996. “El híbrido de Lygia Clark”. En Lygia Clark (Catálogo de exposición). Fundación Antoni Tapies. Barcelona.

Rosaldo, Renato. 1989. Cultura y verdad. Nueva propuesta del análisis social. Grijalbo. México.

Sibilia, Paula. 2006. El hombre postorgánico. Cuerpo, subjetividad y tecnologías digitales. Fondo de Cultura Económica. Buenos Aires.

WACQUANT, LOḮ. 2006 [2000]. Entre las cuerdas. Cuadernos de un aprendiz de boxeador. Siglo XXI Editores. Avellaneda. 